Seventy three fractures were examined at the time of primary treatment under anaesthesia in the first 24 hours after admission to hospital. This group included the 8 fractures with bruising evident at initial presentation. Thirteen other fractures in this group (without evidence of bruising at initial presentation) had developed overt bruising by the time of definitive treatment within 24 hours of hospital admission. Sixteen fractures were reviewed later in the first week for various reasons (for example, change of plaster casts, remanipulations); 4 of these had developed local bruising. Four fractures were reviewed at three weeks when a plaster cast was removed. They were all undisplaced distal radial fractures that had not required manipulative treatment, and bruising was not evident in any of them. Thus 25 fractures (28\%) developed bruising during the first week after trauma.

\section{Comment}

The absence of bruising in children with fractures has been cited as supporting evidence that the force required to fracture the bone was minimal, which implies weakness of the underlying bone-perhaps due to a temporary abnormality such as copper deficiency or subtle forms of osteogenesis imperfecta. ${ }^{13}$ In our study of normal children most fractures (91\%) were not associated with bruising at the time of presentation. Most (72\%) remained without evident bruising in the first week after injury. We therefore suggest that the absence of bruising cannot be taken to imply either underlying bone disease or an increased possibility of non-accidental injury.

Local bruising in acute fractures in childhood is perhaps less common than might be expected. When present it implies that any underlying fracture is likely to be displaced. Its absence is an unreliable sign on which to base a diagnosis of non-accidental injury.

Contributors: GCB had the original idea for this work, checked the analysis of data, and edited the article. NR and MOM jointly collected and analysed data. MOM wrote the article. GCB is guarantor for the study.

Funding: No external funding.

Conflict of interest: None.

1 Paterson CR. Child abuse or copper deficiency? BMJ 1987;295:213. 2 Taitz LS. Child abuse and metabolic bone disease: are they often confused? BMJ 1991;302:1244.

3 Taitz LS. Child abuse: some myths and shibboleths. Hospital Update 1991 May:400-4.

(Accepted 5 May 1998)

\title{
Prevalence of congenital anterior abdominal wall defects in the United Kingdom: comparison of regional registers
}

\author{
D H Stone, Shahnaz Rimaz, W H Gilmour
}

Paediatric

Epidemiology and Community Health

Unit, Department of

Child Health,

University of

Glasgow Yorkhill,

Glasgow G3 8SJ

D H Stone,

director

Shahnaz Rimaz,

postgraduate student

Departments of

Statistics and Public

Health, University

of Glasgow,

Glasgow G12 8RZ

W H Gilmour,

senior lecturer

Correspondence to: Dr Stone

D.H.Stone@clinmed. gla.ac.uk

BMJ 1998;317:1118-9
Recent reports from England and Wales ${ }^{1}$ and Scotland $^{2}$ imply that a gradient of increasing risk of congenital abdominal wall defects may exist from the south to the north of the United Kingdom. We tested this hypothesis by comparing data from a validated public health surveillance system in the west of Scotland with other registers in the United Kingdom. ${ }^{34}$

\section{Subjects, methods, and results}

The Glasgow Register of Congenital Anomalies is a computerised epidemiological database run by the Greater Glasgow Health Board since 1974. A member of the transnational network of EUROCAT (European Registration of Congenital Anomalies) since 1980, it uses multiple sources of ascertainment and subjects all notified anomalies to systematic diagnostic validation. Completed registration forms are transmitted electronically to the EUROCAT central registry in Brussels, where they are checked for completeness and accuracy of coding. ${ }^{3}$ There is no formal time limit for notification. All births and induced abortions following prenatal diagnosis are included in the surveillance. Diagnostic coding is based on the British Paediatric Association's extension to the ninth revision of the International Classification of Diseases.

The numerators were all registered cases of omphalocele (code 75670) and gastroschisis (code 75671 ) in mothers resident within the area covered by the Greater Glasgow Health Board at the time of deliv- ery; cases were included that occurred in live births, still births, and induced abortions for 1980-93 inclusive. Induced abortions were counted in the year of the expected date of delivery had the pregnancy continued. The denominators were the total births to mothers in the area in the relevant time period. Prevalence was calculated by dividing the numbers for each defect by total births. Prevalences were compared using $\chi^{2}$ tests, and ratios of omphalocele to gastroschisis using a $\chi^{2}$ test for heterogeneity of odds ratios.

During the study there were 73 cases of omphalocele (4.08 per 10000 births), of which 34 $(47 \%)$ were induced abortions, and 24 cases of gastroschisis (1.34 per 10000 births), of which 5 (21\%) were induced abortions. The apparently high prevalence of abdominal wall defects in Glasgow relative to other parts of the United Kingdom was due to its exceptionally high rate of omphalocele (table).

\section{Comment}

Our data support the hypothesis of an increasing gradient in the prevalence of congenital anterior abdominal wall defects from the south to the north of the United Kingdom. Whether the phenomenon is real or artefactual (due to varying ascertainment) remains uncertain. In Glasgow the risk of omphalocele seems especially high. The prevalence of omphalocele 
Prevalence of abdominal wall defects in the United Kingdom. Rates are cases per 10000 total births

\begin{tabular}{|c|c|c|c|c|c|c|c|c|c|c|}
\hline \multirow[b]{2}{*}{$\begin{array}{l}\text { Geographical coverage } \\
\text { (reference) }\end{array}$} & \multirow[b]{2}{*}{ Years } & \multirow[b]{2}{*}{$\begin{array}{l}\text { Total No of } \\
\text { births }\end{array}$} & \multirow{2}{*}{$\begin{array}{c}\text { Induced } \\
\text { abortions } \\
\text { included? }\end{array}$} & \multicolumn{2}{|c|}{ Omphalocele } & \multicolumn{2}{|c|}{ Gastroschisis } & \multirow{2}{*}{$\begin{array}{l}\text { Ratio of } \\
\text { omphalocele to } \\
\text { gastroschisis } \\
(95 \% \mathrm{Cl})\end{array}$} & \multicolumn{2}{|r|}{ Both } \\
\hline & & & & No & $\begin{array}{c}\text { Rate } \\
(95 \% \mathrm{CI})\end{array}$ & No & $\begin{array}{c}\text { Rate } \\
(95 \% \mathrm{CI})\end{array}$ & & No & $\begin{array}{c}\text { Rate } \\
(95 \% \mathrm{CI})\end{array}$ \\
\hline Glasgow (current study) & $1980-93$ & 179067 & Yes & 73 & 4.1 (3.1 to 5.0$)$ & 24 & 1.3 (0.8 to 1.9$)$ & 3.0 (1.9 to 4.8$)$ & 97 & 5.4 (4.3 to 6.5$)$ \\
\hline Northern region ${ }^{4}$ & 1988-92 & 201973 & Yes & 43 & 2.1 (1.5 to 2.8$)$ & 56 & 2.8 (2.1 to 3.5$)$ & $0.8(0.5$ to 1.1$)$ & 99 & 4.9 (3.9 to 5.9$)$ \\
\hline Liverpool $^{3}$ & $1980-8$ & 184530 & Yes & 60 & 3.3 (2.4 to 4.1$)$ & 28 & 1.5 (1.0 to 2.1$)$ & 2.1 (1.4 to 3.4$)$ & 88 & 4.8 (3.8 to 5.8$)$ \\
\hline \multirow[t]{2}{*}{ Belfast $^{3}$} & $1980-92$ & 355875 & Yes & 105 & 3.0 (2.4 to 3.5$)$ & 29 & 0.8 (0.5 to 1.1$)$ & $3.6(2.4$ to 5.5$)$ & 134 & 3.8 (3.1 to 4.4$)$ \\
\hline & & & & \multicolumn{2}{|c|}{$\chi^{2}=12.2, P=0.007$} & \multicolumn{2}{|c|}{$\chi^{2}=33.5, \mathrm{P}<0.001$} & $\chi^{2}=33.6, P<0.0001$ & \multicolumn{2}{|c|}{$\chi^{2}=8.5, P=0.036$} \\
\hline Scotland $^{2}$ & $1988-95$ & 515759 & No & 63 & 1.2 (0.9 to 1.5$)$ & 97 & 1.9 (1.5 to 2.3$)$ & $0.6(0.5$ to 0.9$)$ & 160 & 3.1 (2.6 to 3.6$)$ \\
\hline England and Wales ${ }^{1 *}$ & $1987-93$ & 4859221 & No & 448 & 0.9 (0.8 to 1.0$)$ & 539 & 1.1 (1.0 to 1.2$)$ & $0.8(0.7$ to 0.9$)$ & 987 & 2.0 (1.9 to 2.2$)$ \\
\hline
\end{tabular}

*Prevalence of all abdominal wall defects ranged from 1.23 per 10000 births in South West Thames region to 3.11 per 10000 births in Northern region.

in our study is about four times higher than that reported by the Office for National Statistics for England and Wales. However, this striking discrepancy may reflect substantial underascertainment by the Office for National Statistics of cases of omphalocele. ${ }^{4}$ In particular, these national data excluded terminations of pregnancy following prenatal diagnosis, whereas almost half of the cases in our series were terminated. Data from EUROCAT for 1980-92 indicate that the ratio of omphalocele to gastroschisis was $2.5,{ }^{3}$ a value much closer to that of Glasgow (3.0) than that of the Office for National Statistics (0.8). By contrast, the prevalence of gastroschisis in Glasgow is comparable with that of the area covered by the Office for National Statistics, particularly its northern and western regions.

The reported gradient from south to north in the prevalence of abdominal wall defects (especially omphalocele) in the United Kingdom and in Europe as a whole $\mathrm{e}^{5}$ is similar to that observed for neural tube defects and could reflect a common aetiology. Further work is needed to determine the relative influence of ascertainment, maternal factors (such as age, socioeconomic group, and smoking), and underlying secular trends on these geographical variations.
We thank Mrs Hilary Miller and Dr John Womersley of the department of public health, Greater Glasgow Health Board, for their help and support in collating and analysing data from the Glasgow Register of Congenital Anomalies. The EUROCAT network is supported by the European Commission.

Contributors: DHS initiated the study, helped plan the methods, and participated in the analysis, in interpreting data, and in writing the paper. SR helped to conceive the study, collated the data, and contributed to the analysis and writing the paper as part of a wider project on the epidemiology of abdominal wall defects. WHG contributed to methodological aspects of the study, including the analysis, presentation, and interpretation of the results. DHS is guarantor for the study.

Funding: None.

Conflict of interest: None.

1 Tan KH, Kilby MD, Whittle MJ, Beattie BR, Booth IW, Botting BJ. Congenital anterior abdominal wall defects in England and Wales 198793: retrospective analysis of OPCS data. BMJ 1996;313:903-6.

2 Chalmers J, Forrest J, Cant B, Hollinsworth M. Congenital anterior abdominal wall defects. BMJ 1997;314:371-2.

3 EUROCAT Working Group. Surveillance of congenital anomalies in Europe 1980-1992. Brussels: Institute of Hygiene and Epidemiology, 1995. (EUROCAT report 6.)

4 Dillon E, Renwick M, Rankin J. Congenital anterior abdominal wall defects. $B M$ J 1997;314:372.

5 Calzolari E, Bianchi F, Dolk H, Milan M, EUROCAT Working Group. Omphalocele and gastroschisis in Europe: a survey of 3 million births. Am J Med Genet 1995;58:187-94.

(Accepted 27 March 1998)

\section{Fifty years ago}

\section{The hippocratic oath}

The attempt of the World Medical Association to draft a pledge which can be adopted by medical men and women as a short code of ethics has given some publicity to the Hippocratic Oath and also to the mistaken idea that this Oath is sworn to by the newly qualified doctor. It is reproduced in very few histories of medicine, and so we print below the translation of the Pagan Oath given by Mr. W. H. S. Jones in his book The Doctor's Oath (Cambridge University Press, 1924). There are other versions of the Oath, one, for example, "in so far as a Christian may swear it," and also an Arabic version.

\section{Pagan Oath}

"I swear by Apollo Physician, by Asclepius, by Health, by Heal-all, and by all the gods and goddesses, making them witnesses, that I will carry out, according to my ability and judgment, this oath and this indenture:

"To regard my teacher in this art as equal to my parents; to make him partner in my livelihood, and when he is in need of money to share mine with him; to consider his offspring equal to my brothers; to teach them this art, if they require to learn it, without fee or indenture; and to impart precept oral instruction, and all the other learning, to my sons, to the sons of my teacher, and to the pupils who have signed the indenture and sworn obedience to the physicians' Law, but to none other.

"I will use treatment to help the sick according to my ability and judgment, but I will never use it to injure or wrong them.

"I will not give poison to anyone though asked to do so, nor will I suggest such a plan. Similarly I will not give a pessary to a woman to cause abortion. But in purity and in holiness I will guard my life and my art.

"I will not use the knife either on sufferers from stone, but I will give place to such as are craftsmen therein.

"Into whatsoever houses I enter, I will do so to help the sick, keeping myself free from all intentional wrongdoing and harm, especially from fornication with woman or man, bond or free.

"Whatsoever in the course of practice I see or hear (or even outside my practice in social intercourse) that ought never to be published abroad, I will not divulge, but consider such things to be holy secrets.

"Now if I keep this oath and break it not, may I enjoy honour, in my life and art, among all men for all time; but if I transgress and forswear myself, may the opposite befall me." (BMJ 1948;ii:616) 